\title{
Villas, parcs et jardins en Italie, photographies de Patrizia Bellei, textes de Philippe Berthier
}

\section{Jacques Houbert}

\section{(2) OpenEdition}

1 Journals

\section{Édition électronique}

URL : http://journals.openedition.org/studifrancesi/36312

DOI : 10.4000/studifrancesi.36312

ISSN : 2421-5856

Éditeur

Rosenberg \& Sellier

\section{Édition imprimée}

Date de publication : 1 juillet 2005

Pagination : 177

ISSN : 0039-2944

\section{Référence électronique}

Jacques Houbert, «Villas, parcs et jardins en Italie, photographies de Patrizia Bellei, textes de Philippe Berthier », Studi Francesi [En ligne], 145 (XLIX | I) | 2005, mis en ligne le 30 novembre 2015, consulté le 20 avril 2021. URL : http://journals.openedition.org/studifrancesi/36312 ; DOI : https://doi.org/ 10.4000/studifrancesi.36312

Ce document a été généré automatiquement le 20 avril 2021.

\section{(c)}

Studi Francesi è distribuita con Licenza Creative Commons Attribuzione - Non commerciale - Non opere derivate 4.0 Internazionale. 


\title{
Villas, parcs et jardins en Italie, photographies de Patrizia Bellei, textes de Philippe Berthier
}

\author{
Jacques Houbert
}

\section{RÉFÉRENCE}

Av. Vv. Villas, parcs et jardins en Italie, photographies de Patrizia BelleI, textes de Philippe BERTHIER, Tournai, La Renaissance du Livre, 2004, pp. 240.

1 Il existe une telle quantité de livres sur les villas et jardins d'Italie qu'on pourrait se demander s'il est encore possible de renouveler le genre. Pour l'éditeur de ce livre, la question ne s'est pas posée tant il était assuré, en s'adressant à Patrizia Bellei et à Philippe Berthier, de l'affirmative: ce sont des récidivistes. Elle, photographe italienne spécialisée dans la nature et l'art de vivre (jardins, vignobles, décoration, architecture); lui, professeur de littérature française à la Sorbonne nouvelle, l'un des meilleurs connaisseurs du XIX siècle, et de Stendhal en particulier, ont l'habitude d'œuvrer ensemble: ils ont publié, déjà à la Renaissance du Livre, un bel ouvrage consacré au Lac de Côme, sur les traces de Stendhal (2002).

2 Le parcours que nos deux routards d'élite nous proposent aujourd'hui couvre une tout autre surface. Cette fois, ce sont les plus beaux sites de l'Italie entière qu'il nous est donné de découvrir ou de revisiter en leur compagnie. Du Piémont à la Sicile en passant par la région des lacs (l'occasion de revenir sur les rives enchanteresses du lac de Côme et de réécouter la petite musique de Barrès: «Jardins Giulia, Melzi, Sommariva, Serbelloni, syllabes chantantes, terrasses parfumées et lumineuses»), la Vénétie (inoubliables villas palladiennes le long de la Brenta), l'Émilie (un détour obligé par le palais des Farnèse à Colorno pour satisfaire le stendhalien), la Toscane (villégiatures médicéennes dans la campagne florentine, là où se réalise pleinement «la conception humaniste de la villa comme lieu de loisir lettré»), le Latium (avec l'immanquable Villa 
d'Este aux mille jeux d'eau et, toujours à Tivoli, les vestiges de l'antique Villa Adriana chère à Marguerite Yourcenar), la côte amalfitaine (pittoresque Villa Rufolo suspendue sur le Grand Bleu), rien de ce qui compte comme résidences de plaisance parmi les plus remarquables, les plus typiques de la péninsule, n'a échappé à l'objectif de Patrizia Bellei. Un objectif qui n'a rien d'objectif, justement: ses photographies (250) dénotent une personnalité d'artiste accomplie qui la distingue des plats faiseurs de cartes postales, au point que tel paysage épuré des environs de Sienne évoque irrésistiblement, comme le suggère Philippe Berthier, un Nicolas de Staël.

Aussi belle soit l'image, elle ne se suffirait pas à elle-même sans l'apport de l'écrit, indispensable à sa mise en valeur. J'entends, bien sûr, le commentaire original de Philippe Berthier, constitué d'un bref texte de présentation et de morceaux d'inégale longueur, qui, aux précisions historiques et techniques (date de construction, architecte, modifications ultérieures, décoration intérieure, disposition des jardins souvent étagés en terrasses, etc ), ajoutent une touche de poésie où abondent trouvailles verbales et bonheurs d'expression bien dans la manière de notre auteur. Mais aussi, les nombreux passages empruntés à différents auteurs qui émaillent l'ouvrage et dont le choix, révélateur d'une vaste documentation, est si pertinent qu'on les croirait faits sur mesure pour la circonstance. Ne commettez donc pas l'erreur de sauter le texte. Cet homme-là possède son sujet comme pas un. Il sait tout et le dit admirablement. À le lire, on se sentirait presque plus intelligent qu'on ne l'est. 